\title{
Stage and Tissue Specific Expression of Four TCR Subunits in Olive Flounder (Paralichthys olivaceus)
}

\author{
Young Mee Lee, ${ }^{\dagger}$ Jeong-Ho Lee, Jae Koo Noh, Hyun Chul Kim, Choul-Ji Park, \\ Jong-Won Park, In Joon Hwang and Sung Yeon Kim \\ Genetics and Breeding Research Center, NFRDI, Geoje 656-842, Republic of Korea
}

\begin{abstract}
TCR subunits are members of membrane-bound receptors which allow the fast and efficient elimination of the specific fish pathogens have regulated function in adaptive immunity. Sequence structure of TCR subunits have been reported for various teleosts, but the information of each TCR subunit functional characterization through expression analysis in fish was unknown. In this study, we examined the gene expression of TCR subunits in the early developmental stages and observed transcript levels in various tissues from healthy adult olive flounder by RT-PCR. The mRNA expression of alpha subunit was already detected in the previous hatching step. But the transcripts of another TCR subunit were not observed during embryo development and increased after hatching and maintained until metamorphosis at the same level. It was found that all TCR subunits mRNAs are commonly expressed in the immune-related organ such as spleen, kidney and gill, also weak expressed in fin and eye. TCR alpha and beta subunit were expressed in brain, whereas gamma and delta were not expressed same tissue. The sequence alignment analysis shows that there are more than $80 \%$ sequence homology between TCR subunits. Because it has a high similarity of amino acid sequence to expect similar in function, but expression analysis show that will have may functional diversity due to different time and place of expression.
\end{abstract}

Key words : Olive flounder, Paralichthys olivaceus, Adaptive immune response, T cell receptor (TCR), Gene expression, Developmental stage, Immune-related organ

\section{INTRODUCTION}

Recently, land animals reach saturation as the breeding and emphasized the importance of fish as protein sources. Although a catch of fish is increased through successful development of fishing technology and aquaculture, aging of fisheries, recessive of breeding species, breeding density and occurrence of refractory disease lead to increase occurrence frequency of disease and massive mortality. Fish are free-living organisms from the embryonic stage of life in their aquatic environment, this environment is ideal for pathogen attraction (Gomez et al., 2013). Accordingly, protection mechanism is important beginning at the early stages of embryogenesis in fish.

The immune system is biological structures and processes within an organism that protects against disease. To function properly, an immune system must detect a wide variety of agents and distinguish self or non-self. Most pathogens altered host cells and can be recognized by immune cells through expressed pathogen- or dangerassociated molecular patterns (PAMPS or DAMPS, respectively). But pathogens can rapidly evolve and adapt, and thereby avoid detection and neutralization by the immune system. To remove the invaders directly or destroy

\footnotetext{
Manuscript received 20 November 2013, Received in revised form 2 December 2013, Accepted 8 December 2013

${ }^{\dagger}$ Corresponding Author : Jeong-Ho Lee, Genetics and Breeding Research Center, NFRDI, Geoje 656-842, Republic of Korea. Tel. : +82-55-639-5811, Fax : +82-55-639-5809 E-mail : jhlee7124@korea.kr

This is an Open Access article distributed under the terms of the Creative Commons Attribution Non-Commercial License(http://creativecommons. org/licenses/by-nc/3.0) which permits unrestricted non-commercial use, distribution, and reproduction in any medium, provided the original work is properly cited.
} 
their ability to replicate, specialized immune cells of the innate and adaptive responses appeared during evolution (Beck \& Habicht, 1996; Fischer et al., 2013).

The immune system of fish is similar to higher vertebrates, despite having some of the differences. In contrast to higher vertebrates, fish live in aquatic environments from early embryonic stages of life, which are an ideal medium for microorganism growth compared to air. Therefore, fish depend on their innate immune systems for survival. The innate immunity is a fundamental defense mechanism in fish even though a simple and straightforward (Uribe et al., 2011; Bowden et al., 2005) whereas adaptive immune response is highly complex and specific.

The adaptive immune system is composed of a highly specialized, systemic cell which processes to eliminate or prevent pathogenic challenges. Adaptive immunity plays a vital role in protection against recurrent infections by generating memory cells (cell-mediated immunity) and specific soluble and membrane-bound receptors (humoral immunity). These receptor proteins identify molecular patterns that are typical of pathogenic microorganisms, including polysaccharides, lipopolysaccharide (LPS), peptidoglycan bacterial DNA, viral RNA and other molecules that are not normally on the surface of multicellular organisms. A fundamental component of the adaptive immune system is the $\mathrm{T}$ cell which allow the fast and efficient elimination of the specific fish pathogens (Ellis, 2001; Swain, 2006).

Fish possess lymphocyte populations that are analogous to T cells, B cells, cytotoxic cells (similar to natural killer cells), macrophages and polymorphonuclear leukocytes. The immune system of teleosts has sub-populations of $\mathrm{T}$ lymphocytes that exhibit differential responses to mitogens, B cell acute allograft reactions, mixed leukocyte reactions and cooperative interactions between $\mathrm{T}$ cells, B cells and macrophages that are essential for the production of antibodies. Moreover, elasmobranch and teleost fish are the most primitive groups that possess the Major Histocompatibility Complex (MHC) and T cell receptor (TCR) (Manning \& Nakanishi, 1996; Davis \& Bjorkman, 1988;
Miller and Withler, 1998).

The $\mathrm{T}$ cell has a membrane-bound receptor, which is responsible for antigen recognition and is composed of four distinct polypeptide chains (alpha, beta, gamma, and delta). There are two types of $\mathrm{T}$ cell populations based upon their receptor heterodimers (alpha/beta and gamma/ delta). The polypeptide chains are derived from variable $(\mathrm{V})$, joining (J), diversity (D), and constant (C) gene segments. These segments are randomly selected from the germ-line gene pool by a recombination mechanism to generate a wide diversity for antigen recognition (Davis, 1990).

The information on alpha/beta TCR is extensive that Ag-recognition processes, structure, and genetics due to alpha/beta $\mathrm{T}$ cells comprise $~ 90 \%$ of PBLs of humans (Haas et al., 1993; Kronenberg, 1994). The second class of $\mathrm{T}$ cells, termed delta $\mathrm{T}$ cells, is less well understood, as only $1-10 \%$ of human $\mathrm{T}$ cells express gamma/delta TCR. Nonetheless, the gamma/delta $\mathrm{T}$ cells may comprise one-half of the $\mathrm{T}$ cell population in various human tissues (gut, reproductive, and mucosal epithelia) or in the peripheral blood of ungulates. Thus, gamma/delta $\mathrm{T}$ cells are expected to have a fundamentally different role from alpha/beta T cells (Chien et al., 1996; Hayday, 2000).

In this study, we observed the temporal expression of olive flounder TCR subunit genes in the early stage and analyzed expression in the organ in adult fish. This will provide key information for the understanding of fish immune system at early stage of development.

\section{MATERIALS AND METHODS}

\section{Fish maintenance and sample preparation}

Olive flounders were obtained from Genetics and Breeding Research Center, National Fisheries Research and Development Institute (NFRDI; Geoje, Republic of Korea), and maintained in 10 tons flow through tank at $20 \pm 1^{\circ} \mathrm{C}$ under a natural photoperiod. The sample was prepared from various tissues including brain, muscle, fin, eye, liver, spleen, kidney, and gill obtained from 2-year-old healthy 
olive flounder (38 $\mathrm{cm} \pm \mathrm{SEM}, \mathrm{n}=3$ ). Different stages of embryo $(0.92 \pm 0.02 \mathrm{~mm})$, larvae $(2.49 \pm 0.34 \mathrm{~mm})$ and juvenile $(3.5 \pm 0.45 \mathrm{~mm})$ development were described from fish kept at $20^{\circ} \mathrm{C}$ in the tank. The sample of 10 randomly selected embryo or fish were collected including fertilized egg (F), blastula (B), neurula (N) including 0 to 35 days post hatching (dph) (H0, H1, H3, H7, and H35) and immediately frozen in liquid nitrogen, and stored at $-80^{\circ} \mathrm{C}$ until RNA extraction.

\section{Sequence alignment analysis}

The amino acid sequences of the four TCR reported from GenBank, accession numbers are as follows: PoTCRalpha (BAB61895), PoTCR-beta (BAB61899), PoTCR-gamma (BAC00869), PoTCR-delta (BAC00868) and aligned using the GeneDoc tools (Nicholas \& Nicholas, 1997).

\section{RNA extraction and RT-PCR}

Total RNA was extracted using the Trizol Reagent (Invitrogen) according to the manufacturer's protocol. The total RNA concentration was quantified by spectrophotometer and $1 \mu \mathrm{g}$ of total RNA was used for reverse transcribed into cDNA using First Strand cDNA synthesis kit (Roche). The amplification was performed with AmpliTag Gold DNA Polymerase (Applied Biosystems) in thermal Cycler (Bio-Rad) using the following parameters: denaturation at $95^{\circ} \mathrm{C}$ for $10 \mathrm{~min}$ and 30 cycles of reactions of denaturation at $98^{\circ} \mathrm{C}$ for $10 \mathrm{sec}$, annealing at $58^{\circ} \mathrm{C}$ for $30 \mathrm{sec}$, and elongation at $72^{\circ} \mathrm{C}$ for $45 \mathrm{sec}$. An aliquot of each PCR product was subjected to $1.2 \%(\mathrm{w} / \mathrm{v})$ agarose gel electrophoresis and visualized by staining with ethidium bromide. The used PCR primers are listed in Table 1 and $\beta$-actin (ACTB) was used as an internal control.

\section{RESULTS}

\section{Sequence alignment of four TCR subunits}

Nam el al. isolated and identified all four TCR alpha, beta, gamma, and delta cDNAs and genomic clones from olive flounder leukocyte cDNA library (Nam et al., 2003). The sequences are 268 (PoTCR-alpha), 313 (PoTCR-beta), 279 (PoTCR-gamma), 322 (PoTCR-delta) amino acid residues in length. TCR subunits sequence alignment of the olive flounder are presented in Fig. 1. Amino acid sequence homology between TCR subunits is more than $80 \%$ and major structural difference is invisible between TCR subunits. Several important amino acid residues of TCR are conserved well in the variable region $\left(\mathrm{W}^{60}, \mathrm{G}^{67}, \mathrm{D}^{115}\right.$, $\mathrm{A}^{117}, \mathrm{Y}^{119}, \mathrm{C}^{121}$ ).

\section{Expression analysis of olive flounder TCR subunit} genes during early development

We examined the temporal expression of TCR subunits during the indicated early developmental time in the olive flounder. The expression of the TCR alpha subunit gene during the early stages of development is shown in Fig. 2. The mRNA expression of alpha subunit was already detected in the previous hatching step and expression

Table 1. Sequences of primers used for the RT-PCR

\begin{tabular}{lllc}
\hline \hline \multicolumn{1}{c}{ Gene } & Primer & \multicolumn{1}{c}{ Sequence(5'-3') } & $\begin{array}{c}\text { GenBank } \\
\text { Amplicon } \\
\text { accession no. }\end{array}$ \\
\hline \multirow{2}{*}{ PoTCR-alpha } & Forward & TGAACTCGAGGACCAGGACACAA & AB053227 \\
& Reverse & ACCGCCGGATCTTTCTTC & 246 \\
\hline \multirow{2}{*}{ PoTCR-bata } & Forward & CTCTGCCGAAGACTGGTACA & \multirow{2}{*}{ AB053228 } \\
& Reverse & CGTAGACGCTGCTCTTGATG & AB076073 \\
\hline \multirow{2}{*}{ PoTCR-gamma } & Forward & ATCCTGAGAATGGTCTGAAAGACG & \multirow{2}{*}{207} \\
\hline \multirow{2}{*}{ PoTCR-delta } & Reverse & CTGCACAGTAGTACAGAGCAGAG & AB076072 \\
\hline
\end{tabular}


PoTCR-alpha PoTCR-beta PoTCR-del ta PoTCR-Gamma

PoTCR-alpha PoTCR-beta PoTCR-delta PoTCR-Gamma

PoTCR-alpha PoTCR-beta PoTCR-clelta PoTCR-Gamna

PoTCR-alpha PoTCR-beta. PoTCR-delta PoTCR-Gamma
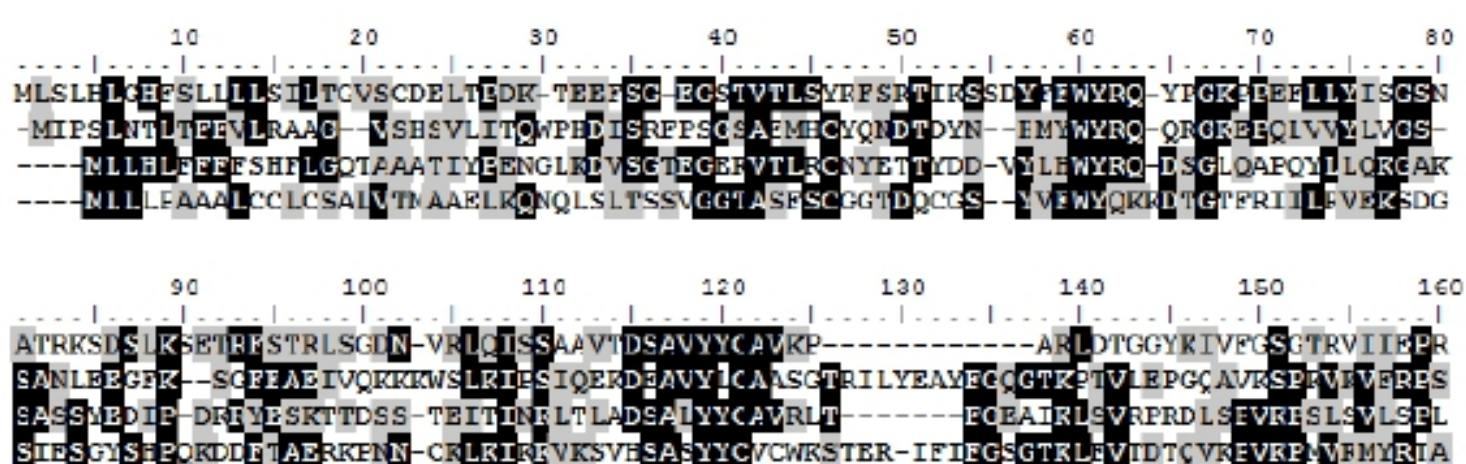

PoTCR-alpha PoTCR-beta PoTCR-delta PoTCR-Gamma
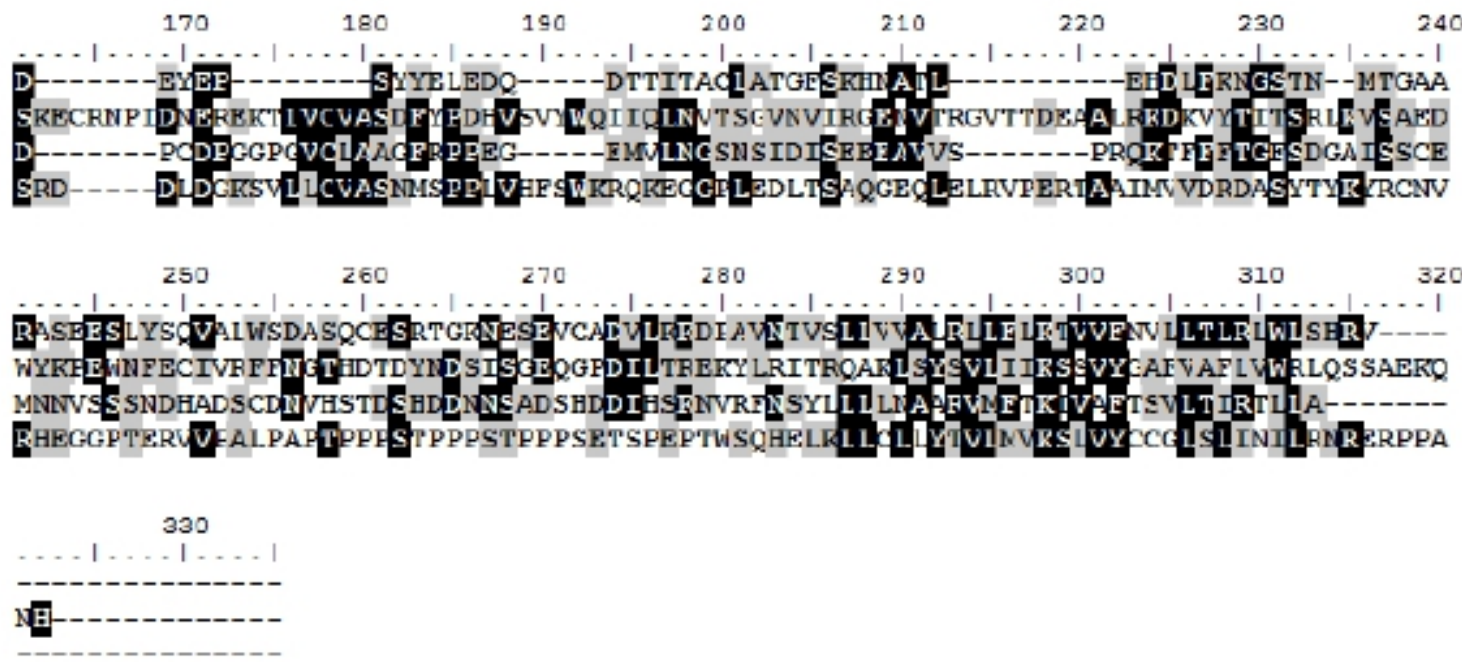

ABIKRTELPPAASTSH

Fig. 1. Amino acid sequence alignment of olive flounder TCR subunits. Amino acid sequences of olive founder TCR subunits were aligned using the GeneDoc program. Genbank accession numbers are as follows: PoTCR-alpha (BAB61895), PoTCR-beta (BAB61899), PoTCR-gamma (BAC00869), PoTCR-delta (BAC00868). Spaces introduced to optimize similarity between the aligned sequences are indicated by hyphens. Importantly, highly conserved amino acid residues are black boxed.

\section{$\begin{array}{llllllll}\text { F } & B & N & \text { H0 } & \text { H1 } & \text { H3 } & \text { H7 } & \text { H35 }\end{array}$}

PoTCR-alpha

PoTCR-beta

PoTCR-gamma

PoTCR-delta

ACTB

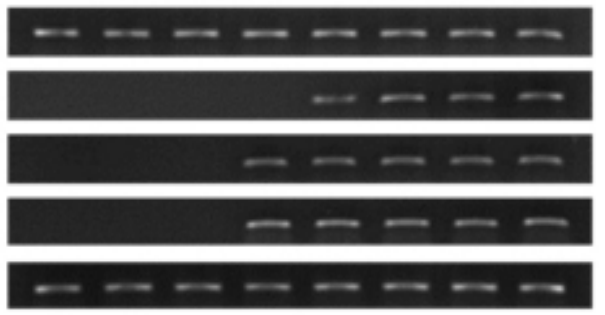

Fig. 2. Expression of olive flounder TCR subunit genes during early developmental stage. Embryo and larva were harvested during post fertilization to 35 days after hatching. The RNA extracted and analyzed by RT-PCR method. Different three stages of embryo including $\mathrm{F}$; fertilized egg, B; blastula, N; neurula including. H0, H1, H3, H7, and H35; from 0 to 35 days post hatching, respectively. level was maintained until metamorphosis at the same level. On the other hand, the expression pattern of another subunit is similar to the overall and expression of gamma and delta subunit were almost identical; the mRNA expressions were not observed during embryo development and the transcriptional level of TCR beta and gamma or delta increased for the first time at $1 \mathrm{dph}$ and $0 \mathrm{dph}$, respectively. Also, the expression level was continuously maintained by a constant amount without increase or decrease until metamorphosis. Although the sequence homology is high, but there is functional difference between subunit. Therefore TCR subunits will important during the early stage to pathogen invasion in acquired immune 
response.

\section{Expression of olive flounder TCR subunit genes from various tissues}

As a step toward evaluating function and localization of various olive flounder TCR molecules, we assessed the expression of the TCR subunit genes in various tissues from 2-year-old healthy olive flounder by RT-PCR. It was found that all TCR subunit mRNAs are significantly expressed in the spleen, kidney and gill. Also, transcript of TCR alpha and beta were expressed in the brain, fin, and eye and was not expressed in muscle. The overall pattern of mRNA expression of TCR gamma and delta was similar to alpha and beta, but was not expressed in the brain.

Spleen, kidney and gill were typical immune organs in fish; kidney is a central organ with key regulatory functions for the immune-endocrine interactions. The spleen as a secondary lymphatic and scavenging organ plays a vital role in haematopoiesis, antigen degradation and antibody production processing (Rauta et al., 2012). Also, gill is the main mucosal surface and immune barriers. Therefore, expression of TCR subunits in immune organ can be expected that involved in the immune response.

\section{DISCUSSIONS}

The immune organs of fish homologues to the mammalian immune system. However, their structural complexity is less, potentially limiting the capability to generate fully functional adaptive immune responses against pathogen invasion (Tort et al., 2003). Moreover, the study of immune responses in fish is incomplete compared to human.

Lower vertebrates, like teleost fish, are the oldest animals with an adaptive immune system based on antibodies, B cells and T cells. (Flajnik \& Kasahara, 2010). T cells play an essential role in cell-mediated immunity and as they interact with the bacteria in mucosal surfaces it seems they are very important in acquisition of tolerance or immunity against the infection (McGhee \& Fujihashi,
2012). Although the value for the study of adaptive immune system is known to be high in fish, functional characterization of individual TCR subunits remains a challenging task.

In previous studies, TCR subunits sequence have been reported for various teleosts including rainbow trout, catfish, zebrafish, and Atlantic cod, olive flounder, bicolor damselfish, Atlantic salmon, carp, turbot, and puffer fish (Partula et al., 1996; Wilson et al., 1998; Hordvik et al., 2004); however, the information of each TCR subunit functional diversity in fishes has not been well documented.

In this study, to information of TCR subunits expression during early stage of development, we analyzed the expression pattern of TCR subunits at the three stages of embryos and five laval stages of days post hatching (Fig. 2). As a result, alpha subunit was expressed in the previous hatched stage, while the another subunits were increased at a later larval stage, although a few difference in time. The differential expression pattern between TCR subunits may indicate the functional difference in immunity. These results suggest that TCR subunits may have important roles in inhibiting the infection during early developmental stage.

The thymus is considered a key organ of the immune system in vertebrates. In this respect the thymus facilitates and regulates the interaction of lymphoid and non-lymphoid

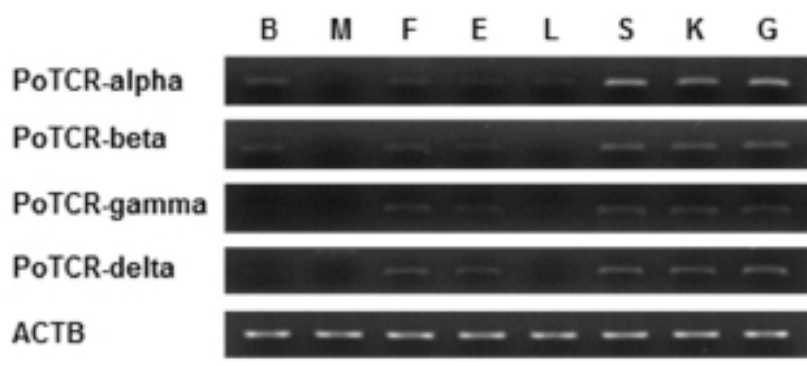

Fig. 3. Expression of olive flounder TCR subunit genes in organ. Expression of olive flounder TCR subunits using mRNA from tissues from 2 year-old healthy olive flounder by RT-PCR. $\beta$-actin (ACTB) as an internal control. B; brain, M; muscle, F; fin, E; eye, L; liver, S; spleen, K; kidney, $\mathrm{G}$; gill, respectively. 
cells. This process is required because of lymphoid organs to guide and control the adaptive immune response through the very precise interaction between antigen presenting cells and lymphocytes. Early development of the thymus in fish has been studied in many diverse teleost species. The development of thymus affected temperature effects on growth and differentiation of the thymus occurs at the middle larval stage at $10 \mathrm{dph}$ in olive flounder, but mRNA expression of TCR subunits was already detected from hatching stage. For such early expression, a role of TCR subunits before the differentiation of thymus in the development of the larvae independent of antigen presentation was suggested.

Also, we examined by RT-PCR using isolated various tissues from 2-year-old healthy olive flounder to investigate the tissue specific expression of the TCR subunit genes. The two different subunits making up the TCR heterodimer (alpha/beta and gamma/delta) were consistently expressed both in immune-related tissues (spleen, kidney, and gill), which are consistent with the function of $\mathrm{T}$ cell receptors. These results suggest that the olive flounder TCR subunits have differential transcriptional regulation in a broader range of tissues than found in mammals.

TCRs are heterodimers consisting of either alpha/beta or gamma/delta polypeptide combinations, and recognize MHC-presented epitopes. Therefore these molecules are useful markers for understanding the mechanisns of epitope recognition and tracing the migration of immune-related responses.

Although immune system of fish have been found highly conservation with mammalian in any part, it is difficult to clearly explain and proper application fish immunology based on the mammalian immune system. The egg and larval stages of marine fishes are the most critical in the successful survival and are extremely sensitive to environmental stress, especially pathogen infection (Rosenthal \& Alderice, 1976). Therefore, further study is specifically required of the fish immune system to establish in its own the functions and characteristics, during early step of development which will provide a clear under- standing of immune response.

\section{ACKNOWLEDGEMENTS}

This work was supported by a grant from the National Fisheries Research and Development Institute (NFRDI), contribution number RP-2013-BT-106.

\section{REFERENCES}

Beck G, Habicht GS (1996) Immunity and the invertebrates. Scientific American 275:60-66.

Bowden TJ, Cook P, Rombout JHWM (2005) Development and function of the thymus in teleosts. Fish and Shellfish Immunology 19:413-427.

Chien YH, Jores R, Crowley MP (1996) Recognition by $\gamma / \delta$ T cells. Annu Rev Immunol 14:511-532.

Davis MM (1990) $\mathrm{T}$ cell receptor gene diversity and selection. Annu Rev Biochem 59:475-496.

Davis MM, Bjorkman PJ (1988) T-cell antigen receptor genes and T-cell recognition. Nature 334:395-402.

Ellis AE (2001) Innate host defense mechanisms of fish against viruses and bacteria. Dev Comp Immunol 25:827-839.

Fischer U, Koppang EO, Nakanishi T (2013) Teleost T and NK cell immunity. Fish \& Shellfish Immunology 35:197-206.

Flajnik MF, Kasahara M (2010) Origin and evolution of the adaptive immune system: genetic events and selective pressures. Nat Rev Genet 11:47-59.

Gomez D, Sunyer JO, Salinas I (2013) The mucosal immune system of fish: The evolution of tolerating commensals while fighting pathogens. Fish \& Shellfish Immunology XX:1-11.

Haas W, Pereira P, Tonegawa S (1993) $\gamma / \delta$ cells. Annu Rev Immunol 11:637-685.

Hayday AC (2000) $\gamma \delta$ Cells: a right time and a right place for a conserved third way of protection. Annu Rev Immunol 18:975-1026.

Hordvik I, Torvund J, Moore L, Endresen C (2004) 
Structure and organization of the Tcell receptor alpha chain genes in Atlantic salmon. Mol Immunol 41: 553-559.

Kronenberg M (1994) Antigens recognized by $\gamma \delta \mathrm{T}$ cells. Curr Opin Immunol 6:64-72.

Manning MJ, Nakanishi T (1996) Cellular Defenses. The Fish Immune System. Academic press. London, England 159-205.

McGhee JR, Fujihashi K (2012) Inside the Mucosal Immune System. PLOS Biology. DOI: 10.1371/journal. pbio.1001397.

Miller KM, Withler RE (1998) The salmonid class I MHC: limited diversity in a primitive teleost. Immunol Rev 166:279-293.

Nam BH, Hirono I, Aoki T (2003) The four TCR genes of teleost fish: the cDNA and genomic DNA analysis of Japanese flounder (Paralichthys olivaceus) TCR alpha-, beta-, gamma-, and delta-chains. J Immunol 170:3081-3090.

Nicholas KB, Nicholas HB Jr (1997) GeneDoc: a tool for editing and annotating multiple sequence alignments. Distributed by the authors.

Partula S, de Guerra A, Fellah JS, Charlemagne J (1996) Structure and diversity of the TCR alpha-chain in a teleost fish. J Immunol 157:207-212.

Rauta PR, Nayak B, Das S (2012) Immune system and immune responses in fish and their role in comparative immunity study: a model for higher organisms. Immunol Lett 148:23-33.

Rosenthal H, Alderdice DF (1976) Sublethal effects of environmental stressors, natural and pollutional, on marine fish eggs and larvae. J Fish Res Bd Can 33:2047-2065.

Swain P (2006) Species defence mechanisms of fish: the basis of antibody production and cell-mediated immune response, P. Swain, P. K. Sahoo, S. Ayyappan (Eds.). Fish and Shellfish Immunology: An Introduction. Narendra Publishing House, Delhi, India 37-46.

Tort L, Balasch JC, Mackenzie S (2003) Fish immune system. A crossroads between innate and adaptive responses. Inmunología 22:277-286.

Uribe C, Folch H, Enriquez R, Moran G (2011) Innate and adaptive immunity in teleost fish: a review. Veterinarni Medicina 56:486-503.

Wilson MR, Zhou H, Bengten E, Clem LW, Stuge TB, Warr GW (1998) T-cell receptors in channel catfish: structure and expression of TCR alpha and beta genes. Mol Immunol 35:545-557. 